\section{KOMPASS}

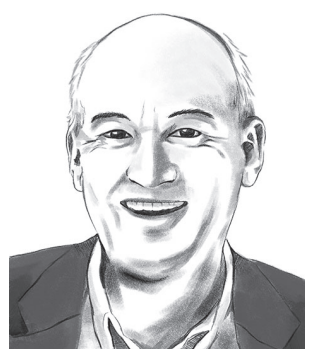

Harald Walach

Poznan/Berlin,

Polen/Deutschland

Normalerweise gehen die Leute ja nicht gerne ins Krankenhaus. Denn es ist ein Ort für Kranke. Das könnte sich bald ändern, denn: $5 G$ kommt! Juchu! Fortschritt! Die ersten Lizenzen sind schon versteigert, die nächste Generation des Mobilfunks ist unterwegs, uns alle zu beglücken. Alle? Nein! Nicht das Krankenhaus. Denn da ist ja - gottseidank und hoffentlich noch lange - mobilfunkfreie Zone. Und wenn es so weitergeht, kommen die Leute ganz von selbst und freiwillig ins Krankenhaus. Weil sie nämlich auf der Suche nach solchen Oasen ohne 5G sind.

$5 \mathrm{G}$ bedeutet: Eine neue Generation des Mobilfunks, höhere Frequenzen, Totalabdeckung. Endlich können wir die Kaffeemaschine ferngesteuert einschalten, bevor wir in Malle in den Flieger steigen und wenn wir dann zurück aus dem Urlaub kommen, erwartet uns ein dampfender Cappuccino und verlängert so die Ferien ein bisschen.

Was den Wenigsten klar ist: $5 \mathrm{G}$ bedeutet auch Totalbestrahlung aus dem All. Denn es werden am Ende etwa 20000 Satelliten um die Erde kreisen, damit die gewünschte Totalabdeckung gewährleistet ist. Denn 5G bietet zwar auf der einen Seite mehr Datendichte, schnelleres Funkinternet, Filme auf dem Smartphone, überall und zu jeder Zeit, ob auf dem Eiger oder am Wasserloch in der Wüste. 5G bedeutet aber auch: Viel höhere Strahlungsenergie, die nur lieferbar ist durch Satellitenbestrahlung und häufige Wiederholung des Signals über ein dichtes Netzwerk an Antennen. Die sieht man dann aber nicht mehr. Denn sie sind kleiner und können in Ampeln, hinter Verkehrsschildern und auf Gipfelkreuzen angebracht werden. Kein

\title{
Ist das Krankenhaus bald das einzige Gesundhaus?
}

Landschaftsästhet kann sich dann mehr beklagen.

Dann wird das Krankenhaus als Funklochenklave endlich zu einem Gesundhaus. Sofern weitsichtige Verwalter und Chefärzte es verhindern, dass auf den Krankenhausdächern Antennen installiert werden. Denn den Wenigsten ist klar, mit welchen Folgen dieser nächste «epochale» Schritt des technologischen Fortschritts verbunden sein könnte.

\section{Daten gibt es zuhauf. Bewusstsein für die Problematik? Nirgendwo.}

Schon jetzt zeigt die epidemiologische Forschung: Nach etwa 20 Jahren Mobilfunknutzung steigt das Risiko eines Glioms um den Faktor 2,5 an [1], nach 7 Jahren das Risiko eines Bauchspeicheldrüsenkrebses um 58\% [2]. Werden Drosophila-Fliegen über eine Woche täglich 6 mal 6 Minuten einer 4GStrahlung von 1,8 GHz ausgesetzt, wie sie jedes moderne Smartphone, Wireless System oder DECT-Telefon verwendet, führt das zu Brüchen in der DNA der Fliegen [3]. Muss uns da noch wundern, dass die Bienen sterben und damit die Basis für ungefähr 1/3 unserer Nahrung bedroht ist [4]? Und noch ein alarmierendes Forschungsergebnis: Die einmalige, 2-stündige Bestrahlung von Mäusen mit einem 1,86 GHz Signal aus handelsüblichen Telefonen führt dazu, dass Genpfade aktiviert werden, die typisch für Krebsentwicklung und Radikalstress sind [5].

Daten gibt es also zuhauf. Bewusstsein für die Problematik? Nirgendwo. Außer im Krankenhaus, hoffentlich. Vielleicht machen sich ja mal ein paar pfiffige Chefs daran, das künftig absolute Alleinstellungsmerkmal von Krankenhäusern als 5G-freie Zone in wissenschaftliche Daten umzumünzen? Man könnte nämlich z.B. in einem Krankenhaus in einem Flügel WLAN installieren, im anderen nicht. Und dann würden die Patienten völlig zufallsverteilt den Stationen zugewiesen und nach einem Jahr, oder vielleicht würde schon eine Woche ausreichen, könnte man harte Parameter messen: Kündigungs- oder Selbstmordraten von Ärzten, Verweildauern von Patienten, Komplikationen, Wiedereinlieferungen, im Bauch vergessene Scheren, sowas. Ich wette wieder mal eine Kiste Burgunder: Der Effekt wäre dramatisch. Aber weil nie irgendwer mit mir wettet, muss ich mir meinen Burgunder wohl wieder selbst kaufen. Das mache ich meistens per Kabel-Internet. Denn WLAN habe ich abgeschafft und Mobiltelefon habe ich, wie die Leser dieser Kolumne sich vielleicht noch erinnern, auch nicht.

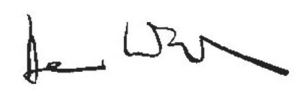

Prof. Dr. Dr. phil. Harald Walach

\section{Literatur}

1 Prasad M, Kathuria P, Nair P et al.: Neurological Sciences 2017;38:797-810.

2 Siqueira EC, Souza FTA, Gomez RS et al.: Journal of Oral Pathology \& Medicine 2016; 46:480-483.

-3 Panagopoulos DJ.: Mutation Research/Reviews in Mutation Research 2019;781:53-62.

4 Sharma VP, Kumar NR.: Science 2010;98: 1376-1378.

- 5 Fragopoulou AF, Polyzos A, Papadopoulou M-D et al.: Brain and Behavior 2018;8:e01001.

\section{KARGER}

Fax +497614520714

information@karger.com

www.karger.com
() 2019 S. Karger GmbH, Freiburg

Accessible online at: www.karger.com/kkp
Prof. Dr. Dr. phil. Harald Walach

CHS Institut

Schönwalder Straße 17, 13347 Berlin, Deutschland

hw@chs-institute.org 